\title{
PPARy Agonist Pioglitazone Inhibits PDGF-induced Pulmonary Artery Smooth Muscle Cells Proliferation and Migration via Modulating TERT
}

\section{Qianqian Zhang}

The First Affiliated Hospital of Xian Jiaotong University https://orcid.org/0000-0002-9564-7346

\section{Wei Feng}

The First Affiliated Hospital of Xian Jiaotong University

\section{Wenhua Shi}

The First Affiliated Hospital of Xian Jiaotong University

\section{Jian Wang}

The First Affiliated Hospital of Xian Jiaotong University

\section{Qingting Wang}

The First Affiliated Hospital of Xian Jiaotong University

\section{Limin Chai}

The First Affiliated Hospital of Xian Jiaotong University

\section{Yuqian Chen}

The First Affiliated Hospital of Xian Jiaotong University

\section{Manxiang Li}

The First Affiliated Hospital of Xian Jiaotong University

Xinming Xie ( $\nabla$ xiexinming1986@163.com)

The First Affiliated Hospital of Xianjiaotong University

\section{Research}

Keywords: Pulmonary artery hypertension, Telomerase, Telomerase reverse transcriptase

Posted Date: February 24th, 2021

DOI: https://doi.org/10.21203/rs.3.rs-233120/v1

License: (c) (i) This work is licensed under a Creative Commons Attribution 4.0 International License. Read Full License 


\section{Abstract}

Background: Vascular remodeling is a significant feature of pulmonary artery hypertension (PAH), characterized by abnormal proliferation and migration of pulmonary arterial smooth muscle cells (PASMCs). Telomerase reverse transcriptase (TERT) as a determinant factor for controlling telomerase activity has been proved to be associated with cell proliferation. This study aims to explore whether TERT participates in the proliferation of PASMCs and the underlying molecular mechanism.

Methods: Primary PASMCs of SD rat were used in this experiment. the proliferation and migration of cells were detected by Cell Counting Kit-8 and transwell assay, respectively. The telomerase activity was determined by Rat TE ELISA KIT. The siRNA transfection was conducted to silence the expression of cMYC. the protein levels of p-Akt, c-MYC and TERT were determined through western blotting.

Results: We found that PDGF upregulated TERT expression and telomerase activation by activation of Akt and upregulation of c-MYC in PASMCs. Inhibition of Akt by LY294002, knockdown of c-MYC by siRNA or suppression of telomerase activity by BIBR1532 repressed PDGF-induced PASMCs proliferation and migration. Furthermore, activation of Peroxisome proliferator-activated receptor Y (PPARY) by pioglitazone suppressed PDGF-induced TERT expression and telomerase activation, leading to inhibition of PASMCs proliferation and migration.

Conclusion: our work demonstrates that TERT mediates PDGF-induced proliferation and migration of PASMCs. In addition, activation of PPARy inhibits these processes via Akt/c-MYC/TERT pathway.

\section{Background}

Pulmonary arterial hypertension (PAH) is a chronic and multidisciplinary disorder characterized by a resting mean pulmonary arterial pressure $\geq 25 \mathrm{mmHg}$, pulmonary artery wedge pressure $\leq 15 \mathrm{mmHg}$, and PVR $>3$ Wood units. The main pathobiology of pulmonary hypertension includes pulmonary vasoconstriction, concentric vascular remodeling and thrombosis in situ[1]. Mounting evidence indicates that excessive proliferation and migration of pulmonary arterial smooth muscle cells lead to development of vascular remodeling in $\mathrm{PAH}$, but the underlying mechanism is still elusive. Thus, exploring novel mechanisms is critical for reversing the progress of PAH and providing specific targets for treating PAH.

Telomerase is characterized as a ribonucleic acid-protein complex TERT, which consists of the noncoding Telomerase RNA Component (TERC), telomerase-associated protein 1 (TEP1) and telomerase reverse transcriptase (TERT)[2,3]. Studies indicate TERT is a rate-limiting factor for controlling telomerase activity. In addition, disfunction of TERT and activation of telomerase are related in various diseases including cardiovascular disease[4], type 2 diabetes mellitus[5], cancer [6], chronic obstructive pulmonary disease[7] as well as PAH [8,9]. However, the underlying molecular mechanism that TERT participated in the development of $\mathrm{PAH}$ remains unclear. 
Peroxisome proliferator-activated receptor y (PPARY) is a member of nuclear hormone receptor superfamily that involves in metabolic homeostasis, cellular proliferation and vascular protection[10]. Activated PPARy protects tissues against excessive lipid overload and controls insulin sensitivity. Thus, pioglitazone as a synthetic PPAR-agonist is widely used to treat type 2 diabetes[11]. Some research has found that activated PPARY is a protective modulator and participates in the regulation of PAH development[12]. Our previous study also found that activation of PPARY in rat results in the amelioration of PAH[13]. Therefore, we consider whether PPARY is involved in the expression of TERT and telomerase activity in PAH. To investigate this hypothesis, we conduct the study to determine the novel molecular mechanism of PPARy in PAH and explore cross-link between PPARY and TERT.

\section{Materials And Methods}

\section{Cell culture}

Primary PASMCs were prepared from main pulmonary arteries of male Sprague-Dawley rats (100-150 g) according the previously reported method[14]. All animals care and procedures were conformed to Xi'an Jiaotong University Animal Care Policy and complied with the Guide for the Care and Use of Laboratory Animals[15]. All experimental protocols used throughout current study were approved by the laboratory Animal Care and Use Committee of Xi'an jiaotong University. Sprague-Dawley rats were anesthetized and lungs were removed rapidly. The main pulmonary arterials were isolated without connective tissues and endothelium, next, we wiped off adventitia and intima repeatedly. The residual pulmonary arteries were minced into small pieces $(0.5-1 \mathrm{~mm} 3)$ and transferred to a culture flask. Cells were incubated with Dulbecco's Modified Eagle Medium (DMEM; Gibco, Grand Isle, NY, USA) containing 10\% fetal bovine serum (FBS; Sijiqing, HangZhou, China), $100 \mathrm{U} / \mathrm{ml}$ penicillin and $100 \mu \mathrm{g} / \mathrm{ml}$ streptomycin in a humidified atmosphere of $5 \% \mathrm{CO} 2$ and $95 \%$ air at $37^{\circ} \mathrm{C}$. At $80 \%$ confluence, cells were trypsinized using $0.25 \%$ trypsin (Invitrogen, Carlsbad, CA, USA) and the 3 th to 6 th generation cells were used through the experiment. For minimizing the effect of serum, cells were cultured in 1\% FBS-DMEM overnight before different treatment. PDGF (10 ng/ml) (Gibco, Carlsbad, USA) was conducted to stimulate cells. Pioglitazone (10 $\mu \mathrm{mol} / \mathrm{I})$ (Cayman Chemical Company, Michigan, USA), was used to active PPARY.

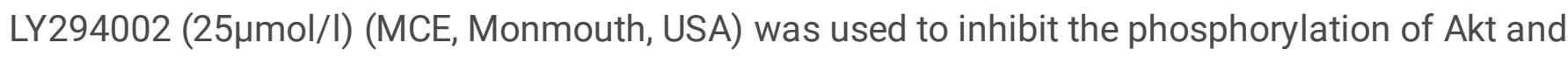
BIBR1532 (5 $\mu \mathrm{mol} / \mathrm{I})$ (APExBIO Techonology, Houston, TX, USA) was conducted to impede the activity of telomerase.

\section{Cell proliferation assay}

Cell Counting Kit-8 (CCK-8) was performed to detect cell proliferation qualitatively according to the manufacturer's protocol. Primarily, PASMCs were plated into 96-well microplates at a concentration of $5 \times 103$ cells/well. After different treatment, each well was added to $10 \mu \mathrm{L}$ of CCK-8 solution for $2 \mathrm{~h}$. Finally, we measured the absorbance at $450 \mathrm{~nm}$ using microplate reader.

\section{Small interfering RNA transfection}


c-MYC expression was knocked down by the c-MYC siRNA purchased from GenePharma (Shanghai, China). PASMCs were incubated in 6-well plates until reaching approximately $30-40 \%$ confluence. Based on the manufacturer's instructions, we diluted siRNA and Lipofectamine 2000 reagent (Invitrogen, Carlsbad, CA, USA) with serum-free DMEM at room temperature for 5 min. cells were treated with the mixture of Lipofectamine ${ }^{\text {TM }} 2000$ and siRNA after incubation for 20 min. Finally, PASMCs were determined for proliferation and harvested for Western blotting.

\section{Transwell assay}

Cell migration was measured by transwell chamber with 8.0- $\mu \mathrm{m}$ pore membrane (Corning, Lowell, MA, USA). After $48 \mathrm{~h}$ transfection, $200 \mu \mathrm{l}$ of cell suspension $(2.5 \times 105 \mathrm{cells} / \mathrm{ml})$ was added into the upper chamber in the serum-free medium. 10\% FBS-DMEM containing PDGF was added to the lower compartment with or without indicated preceding inhibitors. After incubation at $37^{\circ} \mathrm{C}$ for $12 \mathrm{~h}$, the inserts were taken out and fixed with $4 \%(\mathrm{w} / \mathrm{v})$ paraformaldehyde for $20 \mathrm{~min}$. Non-migrated cells in the upper chamber were wiped off using a cotton swab. Then, migrated cells in the lower surface of the membrane were stained with $0.1 \%$ crystal violet and quantified by counting cells under a microscope.

\section{Telomerase activity assay}

The telomerase activity was determined by Rat TE ELISA KIT(FANKEW, Shanghai, China) according to the manufacturer's introduction. Cells lysates acquired by ultrasonication was added into 96-wells plate and covered with a strip and incubated for 30 mins at $37^{\circ} \mathrm{C}$. after Washing, HRP- antibody working solution was added into per well and incubated for 30 mins. Then, the TMB Substrate reacted with HRP- antibody working solution. Finally, the optical density was measured by a microplate reader set to $450 \mathrm{~nm}$.

\section{Immunoblotting}

Cells lysates were obtained by RIPA lysis buffer (HEART, Xi'an, Shaanxi, China). Extracted proteins counting loading buffer were subjected to $10 \%$ SDS-PAGE gel and transferred onto PVDF membranes (Millipore, Billerica, MA). Membranes were blocked in PBS with $3 \%$ bovine serum albumin and incubated with primary antibodies at $4{ }^{\circ} \mathrm{C}$ overnight. The following antibodies were used according to the manufacturer's protocols: Monoclonal antibodies against Akt (\#4691), phospho-Akt (Ser473) (\#13008) and c-MYC (\#9402) (Cell Signaling Technology, 1:1000 dilution), and $\beta$-actin (\#YM3028, ImmunoWay, 1:2000 dilution), and polyclonal antibody against telomerase reverse transcriptase (\#ab191523, Sigma, 1:1000 dilution). After washed three times with TBST and incubated with horseradish peroxidaseconjugated secondary antibody for $1 \mathrm{~h}$ at room temperature, the band was visualized by ChemiDoc XRS system and analyzed by Image-J software.

\section{Statistical analysis}

Data were represented as mean \pm standard error of the mean (SEM) and analyzed by GraphPad Prism 7.0 software. differences between two groups were performed with a Student's $t$-test. differences among 
multiple groups were determined using the one-way ANOVA followed by the Tukey test for multiple comparisons. $\mathrm{P}<0.05$ was considered statistically significant.

\section{Results}

\section{PDGF induces PASMCs proliferation}

To explore the effect of PDGF on PASMCs proliferation, cell viability was measured using CCK-8 at different concentrations $(0,3,10,30,100 \mathrm{ng} / \mathrm{ml})$ or different times $(0,12,24,48,72 \mathrm{~h})$. Figure 1 a shows that cell viability was enhanced with increasing concentration of PDGF and $10 \mathrm{ng} / \mathrm{ml}$ PDGF triggers a 1.29fold increase at $24 \mathrm{~h}$ compared control $(\mathrm{P}<0.05)$. Figure $1 \mathrm{~b}$ indicates that PDGF promoted cell proliferation time-dependently and cell viability reached 1.71 -fold increase at $72 \mathrm{~h}$ over control $(P<0.05)$. The observed results reveal that PDGF induces PASMCs proliferation in a dose and time-dependent manner.

\section{PDGF activates PI3K/Akt signaling pathway and upregulates C-MYC and TERT expressions}

$\mathrm{PI} 3 \mathrm{~K} /$ Akt signaling pathway as a positive regulator mediates PDGF-induced PASMCs proliferation [16]. To understand the mechanisms underlying PDGF-induced PASMCs proliferation, we examined the phosphorylation level of Akt, protein levels of c-MYC and TERT using western blotting. As shown in Figure 2a, b and c, $10 \mathrm{ng} / \mathrm{ml}$ PDGF significantly increased the phosphorylation level of Akt, c-MYC and TERT expressions to 1.50 -fold, 1.63 -fold and 1.84-fold over control, respectively $(P<0.05)$. These results suggest that PDGF activates PI3K/Akt signaling pathway and increases protein levels of c-MYC and TERT in PASMCs.

\section{PI3K/Akt signaling pathway mediates PDGF-induced c-MYC and TERT expressions}

It has reported that the PI3K/Akt signaling pathway promotes the transcription of TERT and cell proliferation by suppressing the function of MAX dimerization protein 1 in MCF-7 Cell Line [17]. Here, to investigate whether it exists in PASMCs, cells were pre-treated with PI3K/Akt inhibitor LY294002 for 30 min and then stimulated with PDGF. We found that LY294002 significantly inhibited Akt phosphorylation to 1.11-fold over control ( $P<0.05$, versus PDGF-treated group Figure 3a). Moreover, the protein level of cMYC was declined to 0.89 -fold over control and TERT expression was dropped to 1.03-fold compared with control $(P<0.05$, versus PDGF-treated group, Figure $3 b$ and $c)$. These results indicate that activation of Akt is responsible for PDGF-induced c-MYC and TERT expressions in PASMCs.

\section{TERT expression is regulated by c-MYC}

c-MYC promotes TERT expression through binding to the TERT proximal promoter in neoplastic cells[18]. To clarify whether c-MYC regulates TERT expression in PASMCs, c-MYC was knocked down by siRNA and protein level of TERT was measured by western blotting. As shown in Figure 4a, the protein level of c-MYC was reduced to $29 \%$ after transfection of c-MYC siRNA in PASMCs for $48 \mathrm{~h}$, meanwhile, control siRNA had no effect on the c-MYC protein level. Figure $4 b$ indicates that PDGF stimulation increased TERT protein 
level to 1.96-fold over control $(\mathrm{P}<0.05)$, while transfection of c-MYC notably reduced PDGF-induced TERT protein level to 1.14-fold compared with control ( $P<0.05$, versus PDGF-treated group). These results suggest the crucial role of c-MYC in PDGF-induced TERT expression.

\section{Activation of PPARY suppresses the effects of PDGF on Akt/c-MYC/TERT axis}

To understand the effect of PPARY on the process of PDGF-induced cell proliferation, cells were pretreated with pioglitazone $(10 \mathrm{mM})$ as PPARy agonist for $30 \mathrm{~min}$ and then stimulated with PDGF for 24 h. As shown in Figure 5a, pioglitazone suppressed the activation of Akt induced by PDGF and the protein level of p-Akt was declined to 1.07-fold compared with control ( $P<0.05$, versus PDGF-treated group).

Figure $5 \mathrm{~b}$ and $\mathrm{C}$ indicates that cells pretreated with pioglitazone dramatically reduced the expression of $\mathrm{C}-$ MYC from 1.55-fold to 0.94 -fold over control and TERT expression from 1.61-fold to 0.97 -fold over control $(P<0.05$, versus PDGF-treated group). All results suggested Activation of PPARY inhibits PDGF-induced expression of p-Akt, c-MYC and TERT.

\section{PDGF induces telomerase activation via Akt/c-MYC/TERT pathway}

To identify whether telomerase activity in PASMCs was triggered by PDGF and was directly mediated via Akt/c-MYC/TERT pathway, cells were incubated with PDGF for $24 \mathrm{~h}$. Figure 6 shows that PDGF significantly increased telomerase activation to 1.45 -fold compared with control $(P<0.05)$. it also indicated that treatment cells with LY294002, BIBR1532, transfection of c-MYC-siRNA or pioglitazone reduced telomerase activation to 1.02-fold, 1.02-fold, 0.90-fold and 0.98-fold over control respectively $(\mathrm{P}<$ 0.05 , versus PDGF-treated group). These results demonstrate PDGF activates telomerase through Akt/cMYC/TERT signaling and activation of PPARY impedes this process.

\section{PDGF-induced telomerase activation promotes cell proliferation and migration by Akt/c-MYC/TERT pathway}

According to the above data, we hypotheses that telomerase activation might mediate cell proliferation and migration by Akt/c-MYC/TERT pathway. We then examined cell viability by CCK-8 assay. As shown in Figure 7a, PDGF increased cell viability to 1.55 -fold compared with control $(P<0.05)$, conversely BIBR1532 reversed this affect and attenuated the cell viability to 1.14-fold compared with control $(\mathrm{P}<$ 0.05 , versus PDGF-treated group) due to the inhibition of telomerase activation. Meanwhile, pre-treatment cells with LY294002, pioglitazone or transfection of c-MYC-siRNA declined cell viability to 1.17-fold, 1.12fold, 1.18-fold over control, respectively ( $P<0.05$, versus PDGF-treated group). Consistently, Figure $7 \mathrm{~b}$ suggested that PDGF stimulation promoted cells migration, whereas BIBR1532 reversed PDGF-induced PASMCs migration and similar effects were observed in LY294002, c-MYC-siRNA and pioglitazone groups. All results prove the hypothesis that telomerase activation facilitates PASMCs proliferation and migration via Akt/c-MYC/TERT pathway

\section{Discussion}


In this study, we identified that PDGF promoted PASMCs proliferation and migration via Akt/c-MYC/TERT pathway. TERT expression and telomerase activity participated in the proliferation and migration in PASMCs, suggesting that TERT might be involved in the pathogenesis of PAH. Our study also found that activation of PPARY suppressed TERT expression and telomerase activity, and then inhibited proliferation and migration of PASMCs, which might be the therapeutic target for treatment of PAH.

PDGF family is considered as growth factors composed of five different disulphide-linked dimers[19]. Among these isoforms, PDGF-BB involves in intracellular activation via binding to two receptor tyrosine kinases, PDGF receptors $\alpha$ and $\beta[20]$. Accumulating evidence has reported that PDGF-BB is a crucial stimulant for VSMC proliferation and migration in vitro $[21,22]$. in addition, continuous PDGFR activation accelerates the development of pulmonary vascular remodeling and pulmonary arterial hypertension in PAH mice $[23,24]$. In this work, our study demonstrated that PDGF-BB promoted PASMCs proliferation and migration.

C-MYC, an oncogenic transcription factor, exerts diverse biological activities such as cell proliferation, apoptosis and cellular metabolism. Previous study has indicated that c-MYC promotes myoblast proliferation and muscle fibre hypertrophy[25]. In our study, we found that c-MYC mediated PDGF-induced proliferation and migration of PASMCs. In cellular processes, c-MYC acts as the integrator at both transcriptional and post-transcriptional levels[26]. It has reported that c-MYC activates transcription of various target genes by binding to E-box sequences located on the promoter regions [25]. In HaCaT cells, chromatin immunoprecipitation assay demonstrates that c-MYC modulates transcriptional activity of TERT through enhancing on the TERT promoter[27]. In the present study, we found that knockdown of cMYC declined PDGF-induced TERT expression and telomerase activation, indicating that C-MYC mediated the upregulation of PDGF-induced TERT expression and telomerase activation in PASMCs.

Telomerase is consisted of noncoding TTAGGG nucleotide repeats, preventing the ends of chromosomes from deterioration[28].Telomerase reverse transcriptase (TERT), a catalytic component of telomerase, remains telomere homeostasis by lengthening telomeric DNA[29]. Study shows that BIBR1532 is a selective telomerase inhibitor[30], which corresponded with our result that BIBR1532 inhibited telomerase activity in PASMCs. In most human somatic cells, TERT gene is suppressed and telomerase activity is inhibited by regulation of the TERT promoter[31]. However, upregulation of TERT and telomerase activation occur during progress in PAH[8]. Consistently, our results showed that PDGF increased the expression of TERT in PASMCs and Inhibition of TERT through BIBR1532 repressed PDGF-induced PASMCs proliferation and migration, suggesting TERT might involve in the process of PASMCs abnormal proliferation in $\mathrm{PAH}$.

PPARY as a ligand-activated transcription factors controls the expression of genes which are essential in cell differentiation and diverse metabolic processes[32]. In adipocytes, hepatocytes and skeletal muscle cell, PPARy indirectly increases insulin-stimulated glucose uptake. Thus, PPARy agonists is recommended as anti-diabetic drugs in the treatment of type 2 diabetes[33]. PPARy is highly expressed not only in adipose tissue, but also in vascular smooth muscle cells. Our previous studies have suggested that 
PPARy activation inhibits proliferation in PASMCs, thereby reverses PAH[34]. In this study, we identified pioglitazone as a PPARY agonist suppressed activation of Akt, c-MYC expression, TERT expression and telomerase activation in PASMCs. At the same time, activated PPARY inhibited proliferation and migration of PASMCs induced by PDGF.

\section{Conclusions}

Taken together, we have demonstrated that PDGF promotes PASMCs proliferation and migration via Akt/c-MYC/TERT pathway. In addition, activation of PPARY suppresses PASMCs proliferation and migration by targeting on this pathway. In light of these findings, TERT might become a potential therapeutic target to inhibit and reverse the development of vascular remodeling in PAH.

\section{Abbreviations}

PAH: Pulmonary artery hypertension

PASMCs: Pulmonary arterial smooth muscle cells

PDGF: Platelet-derived growth factor

TERC: Telomerase RNA Component

TEP1: telomerase-associated protein 1

TERT: telomerase reverse transcriptase

PPARY: Peroxisome proliferator-activated receptor $\mathrm{Y}$

DMEM: Dulbecco's Modified Eagle Medium

FBS: fetal bovine serum

CCK-8: Cell Counting Kit-8

SEM: mean \pm standard error of the mean

\section{Declarations}

\section{Acknowledgements}

The authors thank the National Natural Science Foundation for their support.

\section{Funding}


This work was supported by the National Natural Science Foundation of China (Grant numbers 81800052) and the Natural Science Foundation of Shaanxi Province (2019JQ390)

\section{Contributions}

Xinming Xie were responsible for study concept and design. Qianqian Zhang contributed to conduct experiments. Wei Feng, Wenhua Shi and Jian Wang was responsible for data analysis. All authors contributed to the drafting of this manuscript. All authors read and approved the final manuscript.

\section{Ethics approval and consent to participate}

Not applicable.

\section{Consent for publication}

Not applicable.

\section{Competing interests}

The authors have stated that there are no conflicts of interest.

\section{Availability of data and material}

Not applicable.

\section{Reference}

1. Lau EMT, Giannoulatou E, Celermajer DS, Humbert M Epidemiology and treatment of pulmonary arterial hypertension. Nat Rev Cardiol. 2017.14 (10):603-614. https://www.ncbi.nlm.nih.gov/pubmed/28593996.

2. Zvereva MI, Shcherbakova DM, Dontsova OA Telomerase: structure, functions, and activity regulation. Biochemistry (Mosc). 2010. 75 (13):1563-1583. https://www.ncbi.nlm.nih.gov/pubmed/21417995.

3. Wang Y, Susac L, Feigon J Structural Biology of Telomerase. Cold Spring Harb Perspect Biol. 2019. 11 (12). https://www.ncbi.nlm.nih.gov/pubmed/31451513.

4. Serrano AL, Andres V Telomeres and cardiovascular disease: does size matter? Circ Res. 2004. 94 (5):575-584. https://www.ncbi.nlm.nih.gov/pubmed/15031270.

5. Ma D, Yu Y, Yu X, Zhang M, Yang Y The changes of leukocyte telomere length and telomerase activity after sitagliptin intervention in newly diagnosed type 2 diabetes. Diabetes Metab Res Rev. 2015. 31 (3):256-261. https://www.ncbi.nlm.nih.gov/pubmed/25044768.

6. Jafri MA, Ansari SA, Alqahtani MH, Shay JW Roles of telomeres and telomerase in cancer, and advances in telomerase-targeted therapies. Genome Med. 2016.8 (1):69. https://www.ncbi.nlm.nih.gov/pubmed/27323951. 
7. Bozkus F, Guler S, Simsek S Serum Telomerase Levels and COPD Exacerbations. Respir Care. 2016. 61 (3):359-365. https://www.ncbi.nlm.nih.gov/pubmed/26759422.

8. Shen T, Ma J, Zhang L, Yu X, Liu M, Hou Y, Wang Y, Ma C, Li S, Zhu D Positive feedback-loop of telomerase reverse transcriptase and 15-lipoxygenase-2 promotes pulmonary hypertension. PLoS One. 2013. 8 (12):e83132. https://www.ncbi.nlm.nih.gov/pubmed/24376652.

9. Mouraret N, Houssaini A, Abid S, Quarck R, Marcos E, Parpaleix A, Gary-Bobo G, Dubois-Rande JL, Derumeaux G, Boczkowski J, Delcroix M, Blasco MA, Lipskaia L, Amsellem V, Adnot S Role for telomerase in pulmonary hypertension. Circulation. 2015. 131 (8):742-755. https://www.ncbi.nlm.nih.gov/pubmed/25550449.

10. Semple RK, Chatterjee VK, O'Rahilly S PPAR gamma and human metabolic disease. J Clin Invest. 2006. 116 (3):581-589. https://www.ncbi.nlm.nih.gov/pubmed/16511590.

11. Gross B, Pawlak M, Lefebvre P, Staels B PPARs in obesity-induced T2DM, dyslipidaemia and NAFLD. Nat Rev Endocrinol. 2017. 13 (1):36-49. https://www.ncbi.nlm.nih.gov/pubmed/27636730.

12. Legchenko E, Chouvarine P, Borchert P, Fernandez-Gonzalez A, Snay E, Meier M, Maegel L, Mitsialis SA, Rog-Zielinska EA, Kourembanas S, Jonigk D, Hansmann G PPARgamma agonist pioglitazone reverses pulmonary hypertension and prevents right heart failure via fatty acid oxidation. Sci Transl Med. 2018. 10 (438). https://www.ncbi.nlm.nih.gov/pubmed/29695452.

13. Xie X, Wang G, Zhang D, Zhang Y, Zhu Y, Li F, Li S, Li M Activation of peroxisome proliferatoractivated receptor gamma ameliorates monocrotaline-induced pulmonary arterial hypertension in rats. Biomed Rep. 2015.3 (4):537-542. https://www.ncbi.nlm.nih.gov/pubmed/26171162.

14. Wu Y, Liu L, Zhang Y, Wang G, Han D, Ke R, Li S, Feng W, Li M Activation of AMPK inhibits pulmonary arterial smooth muscle cells proliferation. Exp Lung Res. 2014. 40 (5):251-258. https://www.ncbi.nlm.nih.gov/pubmed/24809794.

15. Provencher S, Archer SL, Ramirez FD, Hibbert B, Paulin R, Boucherat O, Lacasse Y, Bonnet S Standards and Methodological Rigor in Pulmonary Arterial Hypertension Preclinical and Translational Research. Circ Res. 2018. 122 (7):1021-1032. https://www.ncbi.nlm.nih.gov/pubmed/29599278.

16. Krymskaya VP, Snow J, Cesarone G, Khavin I, Goncharov DA, Lim PN, Veasey SC, Ihida-Stansbury K, Jones $\mathrm{PL}$, Goncharova EA mTOR is required for pulmonary arterial vascular smooth muscle cell proliferation under chronic hypoxia. FASEB J. 2011. 25 (6):1922-1933. https://www.ncbi.nlm.nih.gov/pubmed/21368105.

17. Chou CK, Lee DF, Sun HL, Li LY, Lin CY, Huang WC, Hsu JM, Kuo HP, Yamaguchi H, Wang YN, Liu M, Wu HY, Liao PC, Yen CJ, Hung MC The suppression of MAD1 by AKT-mediated phosphorylation activates MAD1 target genes transcription. Mol Carcinog. 2009. 48 (11):1048-1058. https://www.ncbi.nlm.nih.gov/pubmed/19526459.

18. Wu KJ, Grandori C, Amacker M, Simon-Vermot N, Polack A, Lingner J, Dalla-Favera R Direct activation of TERT transcription by c-MYC. Nat Genet. 1999. 21 (2):220-224. https://www.ncbi.nlm.nih.gov/pubmed/9988278. 
19. Heldin CH Targeting the PDGF signaling pathway in tumor treatment. Cell Commun Signal. 2013. 11:97. https://www.ncbi.nlm.nih.gov/pubmed/24359404.

20. Fredriksson L, Li H, Eriksson U The PDGF family: four gene products form five dimeric isoforms. Cytokine Growth Factor Rev. 2004. 15 (4):197-204. https://www.ncbi.nlm.nih.gov/pubmed/15207811.

21. Lu QB, Wan MY, Wang PY, Zhang CX, Xu DY, Liao X, Sun HJ Chicoric acid prevents PDGF-BB-induced VSMC dedifferentiation, proliferation and migration by suppressing ROS/NFkappaB/mTOR/P70S6K signaling cascade. Redox Biol. 2018. 14:656-668. https://www.ncbi.nlm.nih.gov/pubmed/29175753.

22. Barst RJ PDGF signaling in pulmonary arterial hypertension. J Clin Invest. 2005.115 (10):2691-2694. https://www.ncbi.nlm.nih.gov/pubmed/16200204.

23. Dahal BK, Heuchel R, Pullamsetti SS, Wilhelm J, Ghofrani HA, Weissmann N, Seeger W, Grimminger F, Schermuly RT Hypoxic pulmonary hypertension in mice with constitutively active platelet-derived growth factor receptor-beta. Pulm Circ. 2011.1 (2):259-268.

https://www.ncbi.nlm.nih.gov/pubmed/22034611.

24. Schermuly RT, Dony E, Ghofrani HA, Pullamsetti S, Savai R, Roth M, Sydykov A, Lai YJ, Weissmann N, Seeger W, Grimminger F Reversal of experimental pulmonary hypertension by PDGF inhibition. J Clin Invest. 2005. 115 (10):2811-2821. https://www.ncbi.nlm.nih.gov/pubmed/16200212.

25. Luo W, Chen J, Li L, Ren X, Cheng T, Lu S, Lawal RA, Nie Q, Zhang X, Hanotte O c-Myc inhibits myoblast differentiation and promotes myoblast proliferation and muscle fibre hypertrophy by regulating the expression of its target genes, miRNAs and lincRNAs. Cell Death Differ. 2019. 26 (3):426-442. https://www.ncbi.nlm.nih.gov/pubmed/29786076.

26. Boxer LM, Dang CV Translocations involving c-myc and c-myc function. Oncogene. 2001. 20 (40):5595-5610. https://www.ncbi.nlm.nih.gov/pubmed/11607812.

27. Zheng L, Suzuki H, Nakajo Y, Nakano A, Kato M Regulation of c-MYC transcriptional activity by transforming growth factor-beta 1-stimulated clone 22. Cancer Sci. 2018. 109 (2):395-402. https://www.ncbi.nlm.nih.gov/pubmed/29224245.

28. Blasco MA Telomeres and human disease: ageing, cancer and beyond. Nat Rev Genet. 2005. 6 (8):611-622. https://www.ncbi.nlm.nih.gov/pubmed/16136653.

29. Greider CW, Blackburn EH Identification of a specific telomere terminal transferase activity in Tetrahymena extracts. Cell. 1985. 43 (2 Pt 1):405-413.

https://www.ncbi.nlm.nih.gov/pubmed/3907856.

30. Ding X, Cheng J, Pang Q, Wei X, Zhang X, Wang P, Yuan Z, Qian D BIBR1532, a Selective Telomerase Inhibitor, Enhances Radiosensitivity of Non-Small Cell Lung Cancer Through Increasing Telomere Dysfunction and ATM/CHK1 Inhibition. Int J Radiat Oncol Biol Phys. 2019. 105 (4):861-874. https://www.ncbi.nlm.nih.gov/pubmed/31419512.

31. Shay JW, Wright WE Telomeres and telomerase: three decades of progress. Nat Rev Genet. 2019. 20 (5):299-309. https://www.ncbi.nlm.nih.gov/pubmed/30760854. 
32. Yousefnia S, Momenzadeh S, Seyed Forootan F, Ghaedi K, Nasr Esfahani MH The influence of peroxisome proliferator-activated receptor gamma (PPARgamma) ligands on cancer cell tumorigenicity. Gene. 2018. 649:14-22. https://www.ncbi.nlm.nih.gov/pubmed/29369787.

33. Marion-Letellier R, Savoye G, Ghosh S Fatty acids, eicosanoids and PPAR gamma. European journal of pharmacology. 2016. 785:44-49. https://www.ncbi.nlm.nih.gov/pubmed/26632493.

34. Li F, Zhu Y, Wan Y, Xie X, Ke R, Zhai C, Pan Y, Yan X, Wang J, Shi W, Li M Activation of PPARgamma inhibits HDAC1-mediated pulmonary arterial smooth muscle cell proliferation and its potential mechanisms. European journal of pharmacology. 2017. 814:324-334. https://www.ncbi.nlm.nih.gov/pubmed/28867608.

\section{Figures}


a

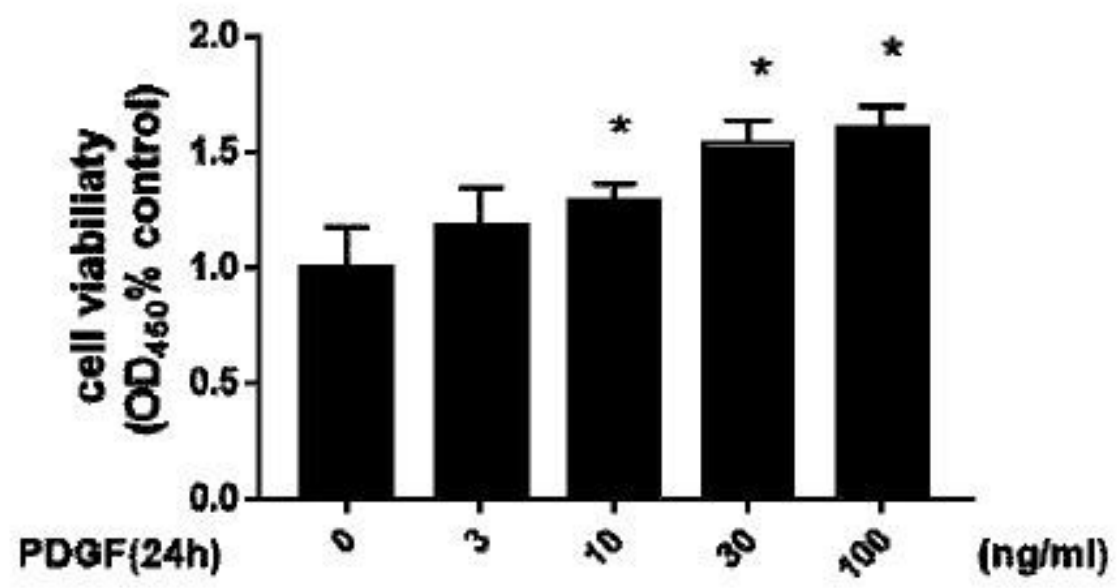

b

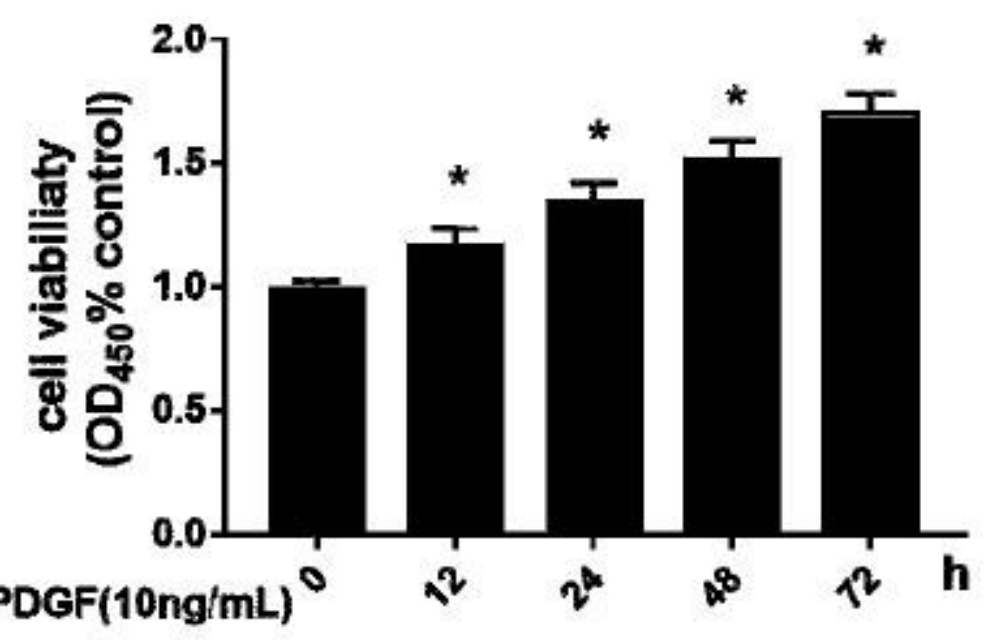

Figure 1

PDGF promotes PASMCs proliferation. (a) Cells were stimulated with PDGF for $24 \mathrm{~h}$, which concentration ranged from 0 to $100 \mathrm{ng} / \mathrm{ml}$. Cell proliferation was detected by CCK-8 assay (n=6 per group). (b) $10 \mathrm{ng} / \mathrm{ml}$ PDGF stimulated PASMCs for different time $(0,12,24,48,72 \mathrm{~h})$. Cell proliferation was detected by CCK-8 assay ( $\mathrm{n}=6$ per group). ${ }^{\star} \mathrm{P}<0.05$ versus control. 
a p-Akt Akt

Con PDGF

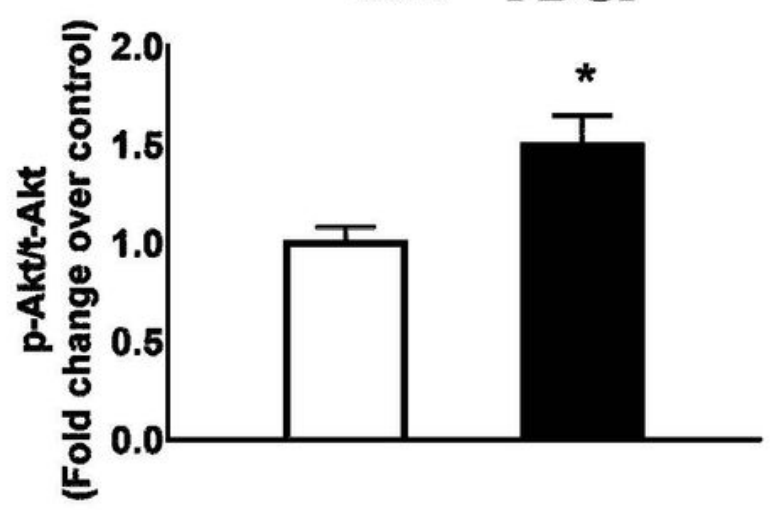

C

TERT

B-actin

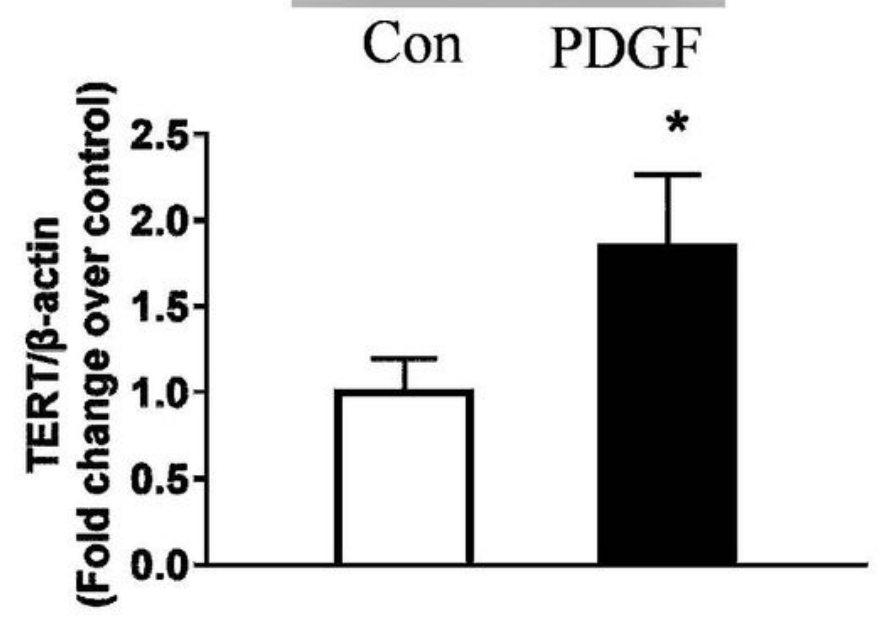

\section{c-MYC}

ß-actin

\section{Con PDGF}

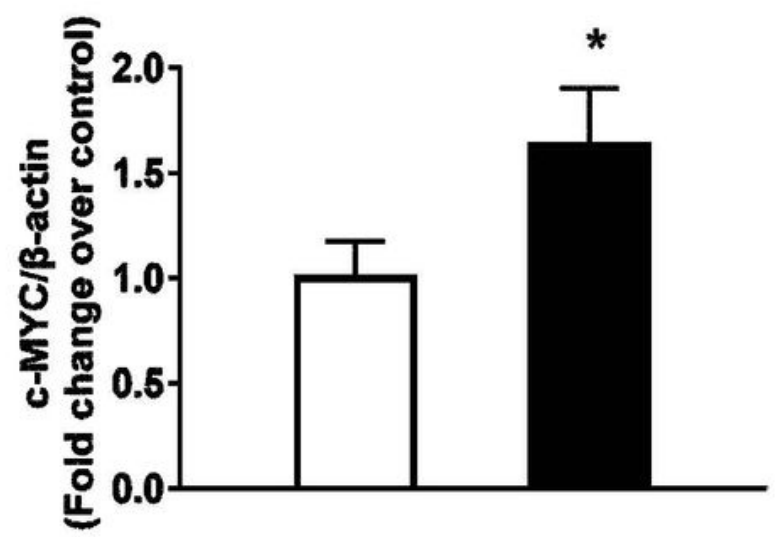

\section{Figure 2}

PDGF induces the activation of Akt and upregulation of c-MYC and TERT. $10 \mathrm{ng} / \mathrm{ml} \mathrm{PDGF}$ treated cells for $24 \mathrm{~h}$. The expression of p-Akt (a), c-MYC(b) and TERT(c) were determined by western blotting. t-Akt or $\beta$ actin served as a loading control ( $n=3$ per group, ${ }^{*} \mathrm{P}<005$ versus control). 


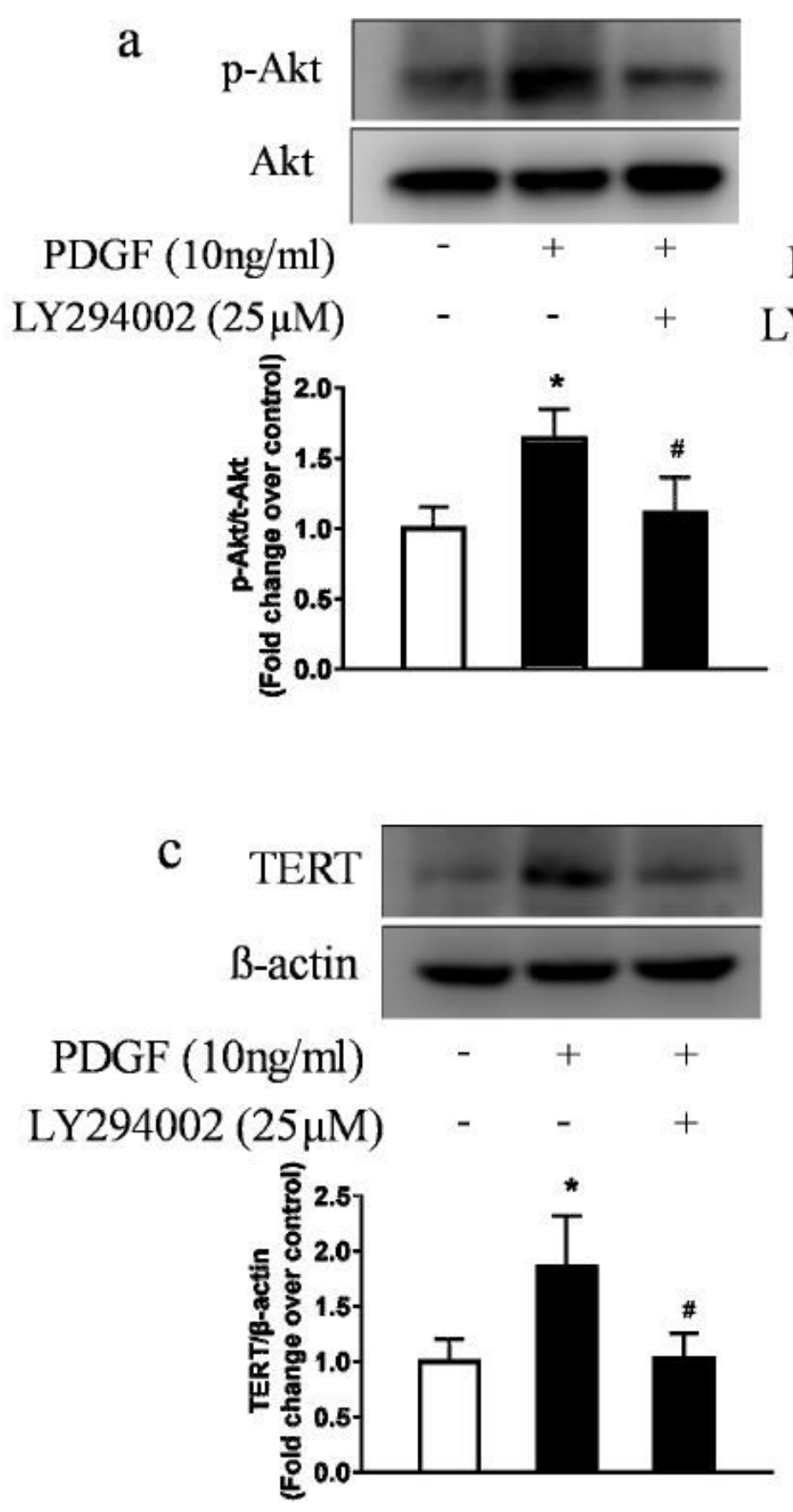

Figure 3

Akt mediates the PDGF-induced upregulation of c-MYC and TERT. LY294002 was pre-treated cells for 30 min before PDGF stimulation. The expression of p-Akt(a), c-MYC(b) and TERT(c) were measured using western blotting. $t$-Akt or $\beta$-actin served as loading control. ( $n=3$ per group). ${ }^{*}<<0.05$ versus control. \# $P$ $<0.05$ versus PDGF-treated group. 

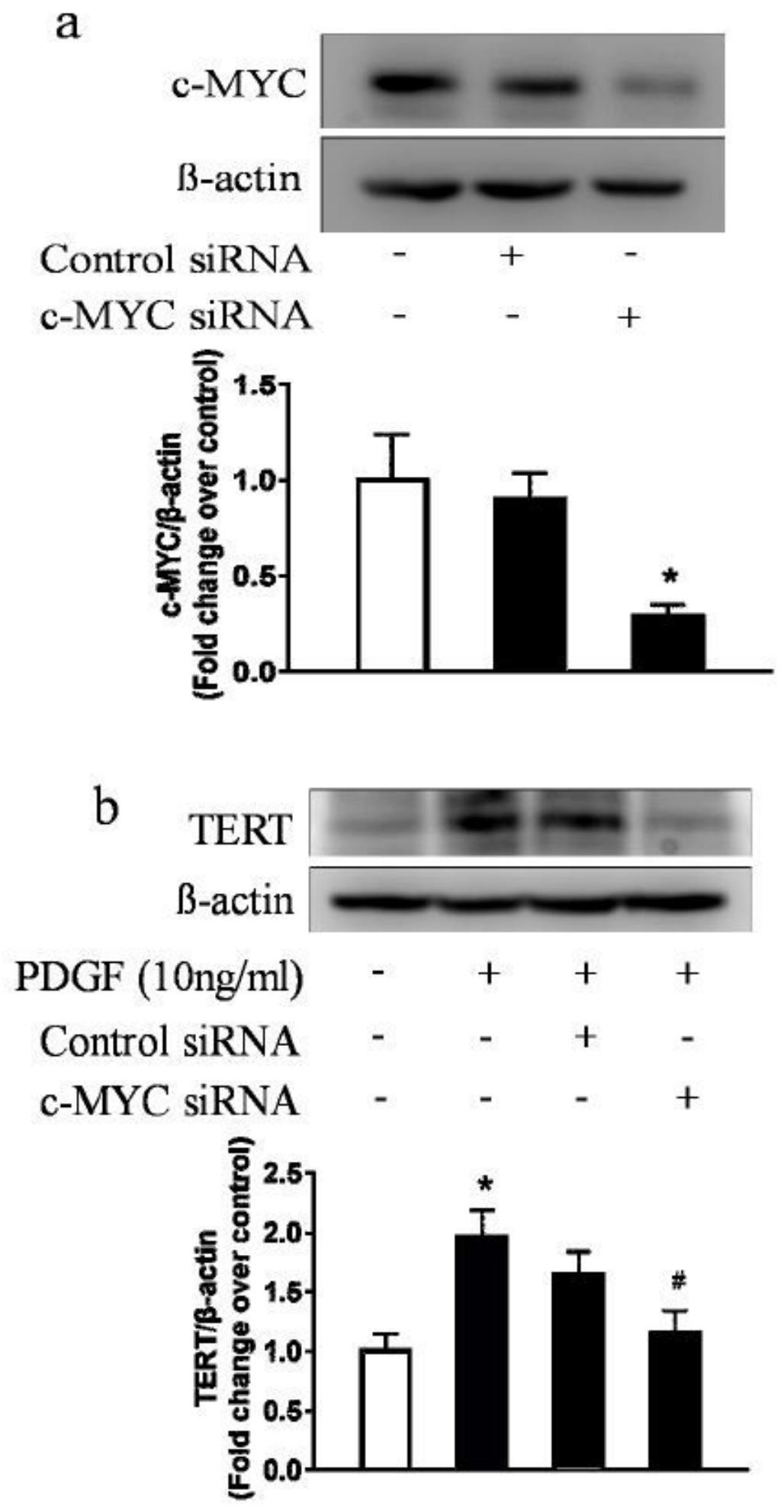

Figure 4

C-MYC mediates the expression of TERT in PDGF-induced PASMCs proliferation. (a) C-MYC siRNA or nontargeting siRNA were transfected into cells, the silencing effect was detected by western blotting. $\beta$-actin served as loading control. ( $n=3$ per group). ${ }^{\star} \mathrm{P}<0.05$ versus control. (b) c-MYC siRNA or non-targeting siRNA were prior transfected to cells and then treated with PDGF for $24 \mathrm{~h}$. TERT protein level was 
measured using western blotting. $\beta$ - actin served as loading control ( $n=4$ per group). * $P<0.05$ versus control. \#P $<0.05$ versus PDGF-treated group.

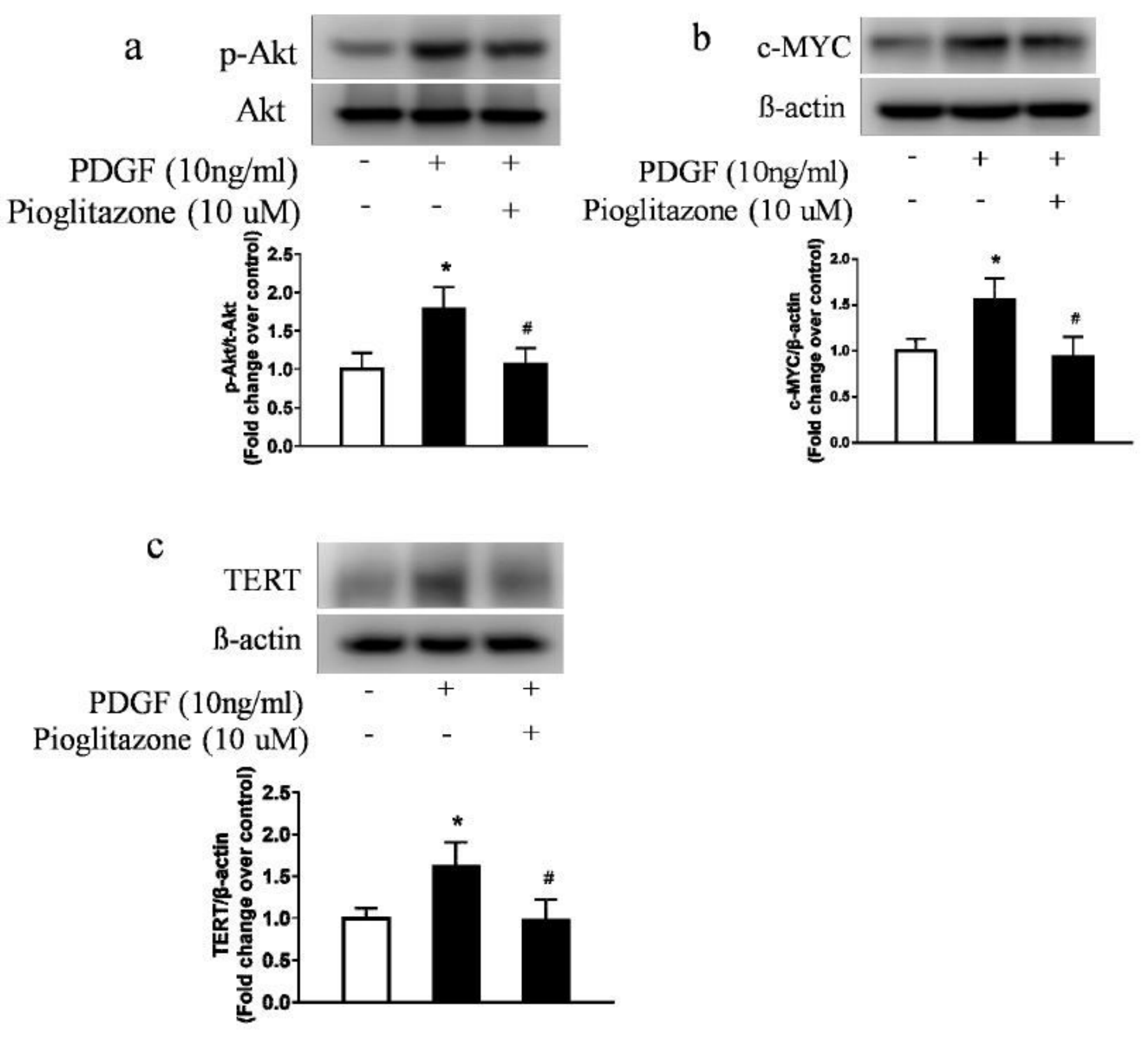

Figure 5

Activation of PPARy inhibits Akt/c-MYC/TERT signal pathway in PASMCs. Pioglitazone (10 mM) pretreated PASMCs for 30 min before PDGF stimulation. (a) Phosphorylation of Akt was determined by western blotting ( $\mathrm{n}=3$ per group). (b) the expression of $\mathrm{c}-\mathrm{MYC}$ was detected using western blotting ( $\mathrm{n}=3$ per group). (c) TERT protein level was measured by western blotting ( $n=3$ per group). ${ }^{*}<0.05$ versus control, $\#$ P $<0.05$ versus PDGF -treated cells. 


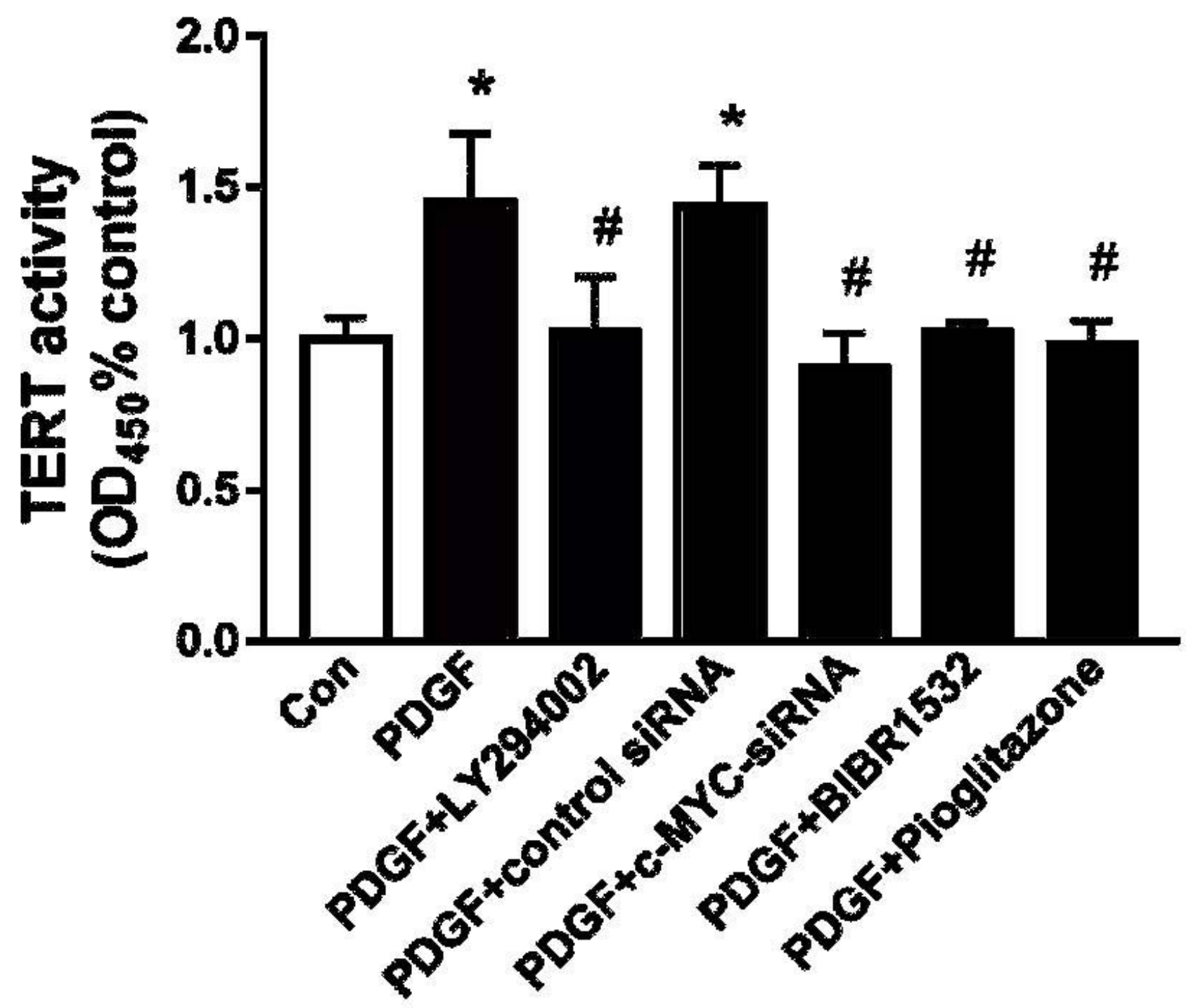

Figure 6

Activation of PPARy suppresses PDGF-induced telomerase activation in PASMCs. Cells were preincubated with pioglitazone (10 mM) for $30 \mathrm{~min}$, LY294002 for $30 \mathrm{~min}$, BIBR1532 for $2 \mathrm{~h}$, prior transfected with non-targeting siRNA or c-MYC siRNA for 24 before PDGF stimulation $10 \mathrm{ng} / \mathrm{ml}$ for $24 \mathrm{~h}$. telomerase activity was measured using Rat TE ELISA KIT ( $n=6$ per group). ${ }^{*} P<0.05$ versus control, \#P $<0.05$ versus PDGF -treated cells. 
$\mathrm{a}$

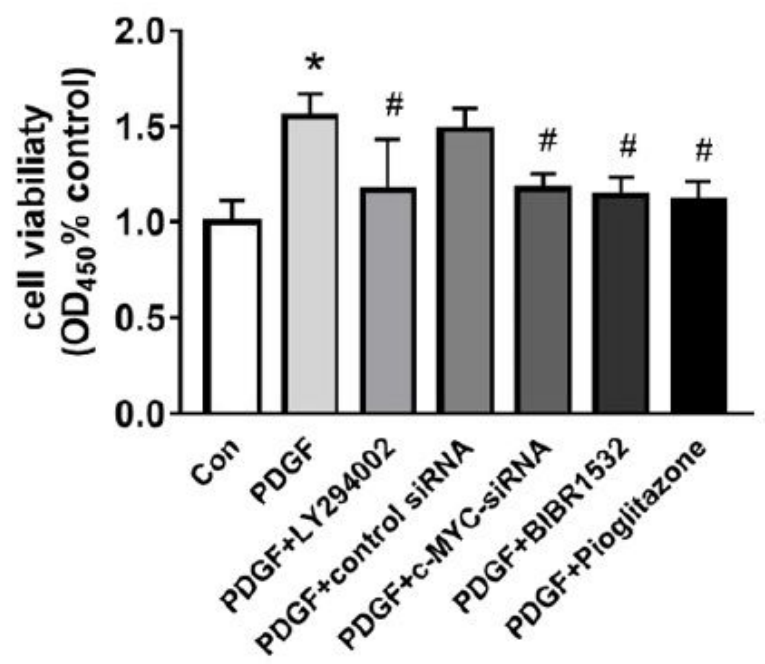

b

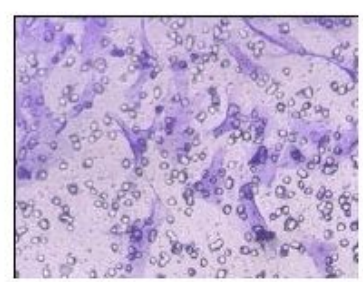

Control

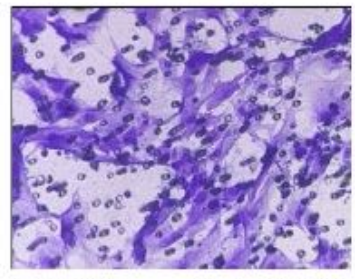

PDGF + control siRNA PDGF + c-MYC siRNA PDGF+BIBR1532

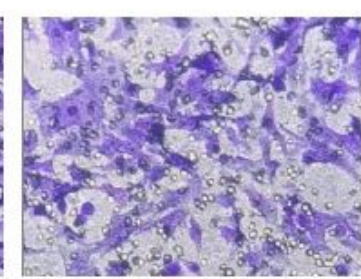

PDGF + LY294002

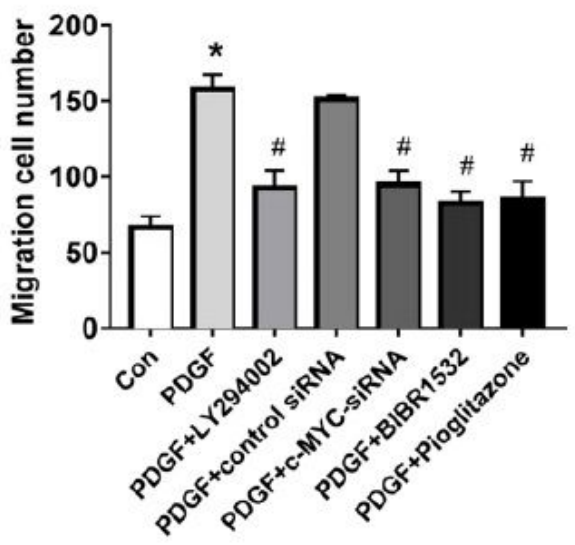

Figure 7

PDGF induces PASMCs proliferation and migration via Akt/c-MYC/TERT axis. Cells were pre-incubated with pioglitazone (10 mM) for 30 min, LY294002 for $30 \mathrm{~min}$, BIBR1532 for $2 \mathrm{~h}$, prior transfected with nontargeting siRNA or C-MYC siRNA for 24 before PDGF stimulation $10 \mathrm{ng} / \mathrm{ml}$ for $24 \mathrm{~h}$. (a) The proliferation of PASMCs was detected through CCK-8 ( $n=6$ per group). (b) The migration of PASMCs was examined by transwell assay ( $n=3$ per group). $P<0.05$ versus control, \#P $<0.05$ versus PDGF -treated cells. 